$\mathbb{T}$ Periodica Polytechnica Chemical Engineering

61(3), pp. 200-205, 2017

https://doi.org/10.3311/PPch.9580

Creative Commons Attribution (i)

RESEARCH ARTICLE

\section{Optimization of Ultrasound-Assisted Extraction of Total Extractive Substances from Galium verum $\mathrm{L}$.}

\author{
Katarina M. Rajković ${ }^{1,2 *}$, Sanja Jeremić ${ }^{3}$, Petar S. Milić ${ }^{4}$, \\ Marina Kostićs ${ }^{5}$ Valentina Arsić-Arsenijević ${ }^{6}$, Marijana Gavrilović2 \\ Boro Krstić ${ }^{7}$
}

Received 08 June 2016; accepted after revision 30 September 2016

\begin{abstract}
Ultrasound-assisted extraction (US-AE) of total extractive substances from the herb Lady's Bedstraw (Galium verum L.) is useful extraction method for its application in food manufacturing. The effect of different temperatures (T) and solventto-solid ratios (S) on the US-AE extraction yield was studied in this paper. The influence and optimum of the operating parameters (T and $S$ ) was investigated using response surface methodology (RSM). The $T$ and $S$ had impact on extraction yield. RSM showed that the optimal extraction parameters, which gave a maximum extraction yield of $18.7 \%$, were $T$ of $40^{\circ} \mathrm{C}$ and $S$ of $30 \mathrm{~kg} \mathrm{~kg}^{-1}$. Using modeled optimized conditions, detected relative difference between predicted and experimental yield was $3.3 \%$. RSM successfully predicted optimal parameters and proved as useful tool for standardization of extraction conditions for bioactive components from plants important for food industry.
\end{abstract}

\section{Keywords}

Galium verum L., Optimization, Response surface methodology, Ultrasound-assisted extraction

${ }^{1}$ Faculty of Pharmacy, University of Bijeljina,

Pavlovića put bb, 76300 Bijeljina, Bosnia and Herzegovina

${ }^{2}$ High Tehnical and Technological School for Professional Studies,

Kosančićeva 36, 37000 Kruševac, Serbia

${ }^{3}$ Institute of Molecular Genetics and Genetic Engineering, University of Belgrade, Vojvode Stepe 444a, 11010 Belgrade, Serbia

${ }^{4}$ High Medical School of Professional Studies, Ćuprija, Serbia

${ }^{5}$ Institute for Biological Research „Sinisa Stankovic”, University of Belgrade, Bulevar Despota Stefana 142, 11060 Beograd, Serbia

${ }^{6}$ National Reference Medical Mycology Laboratory, Institute of Microbiology and Immunology, Faculty of Medicine, University of Belgrade,

dr Subotića 1, 11000 Belgrade, Serbia

${ }^{7}$ Faculty of Agriculture, University of Bijeljina,

Pavlovića put bb, 76300 Bijeljina, Bosnia and Herzegovina

*Corresponding author, e-mail: katar1970@yahoo.com

\section{Introduction}

Serbian flora represents an abundant resource of interesting plants, including genus Galium (Rubiaceae), represented with 37 species [1, 2]. Among them the herb Lady`s Bedstraw (Galium verum L.) is the most frequently used in traditional medicine [3] and food manufacturing [4]. The G. verum is widely used to coagulate milk and, in Scotland, the plant is still used as a dye and in cheese manufacturing [4]. Chemical composition and biological activity is what makes this plant very interesting [5-12].

Recently, improved methods have been developed to extract bioactive compounds from Galium species [13-16]. Compared with conventional solvent extraction methods, the use of ultrasound-assisted extraction (US-AE) for extraction of bioactive compounds has been reported as faster, more efficient, and solvent-saving technique $[15,17,18]$. Ultrasonic waves generate a cavitation effect in the solvent, resulting in faster movement of molecules and higher penetration of the solvent into the target material $[19,20]$.

Rebirth of research that occurred lately demonstrated the implementation of modeling tools in order to simulate US-AE of bioactive compounds from different sources [18, 21, 22]. Modeling followed by optimization of US-AE contributed to its further improvement by increasing the extraction yield for Galium species $[13,15,16]$. When yield of extractive substances from plant is influenced by several parameters response surface methodology (RSM) is the most commonly used for development, improvement and optimization of extraction processes [22-25]. Therefore, the objectives of this study were to estimate the influence and combined effects of important extraction parameters such as temperature $(T)$ and solvent-to-solid ratio $(S)$, as well as to optimize operational parameters of US-AE using RSM in order to obtain a maximal possible extraction yield from $G$. verum.

\section{Materials and Methods}

\subsection{Sample collection and plant extraction}

Aerial parts of white lady's bedstraw (G. verum L.) were collected during the blooming (Vlasina locality, southeast region of Serbia). The specimen of this plant is conserved at 
the Herbarium of the University of Belgrade - BEOU under the number 17071. The plant was dried in a shadow and grounded immediately prior to extraction (average plant particle size: $0.75 \mathrm{~mm})$.

\subsection{Extraction equipment and procedures}

An ultrasonic bath (Sonic, Niš, Serbia, power 120 W, frequency $40 \mathrm{kHz}$ ) was used for indirect ultrasonication. Water was circulated through the ultrasonic bath by a pump from a thermostated water bath, which was kept at a constant temperature. The ultrasonic power input was $7.3 \pm 0.3 \mathrm{~W}[15]$.

The grounded plant material was mixed with $96 \%$ (v/v) ethanol in an Erlenmeyer flask, equipped with a reflux condenser. The ultrasound-assisted extraction was performed for $80 \mathrm{~min}$ at 20, 28, 34 and $40{ }^{\circ} \mathrm{C}$ and $S$ varied between 5 and $40 \mathrm{~kg} \mathrm{~kg}^{-1}$. After $80 \mathrm{~min}$, the suspension of plant particles in solvent was cooled to the room temperature, taken from the flask and filtered under vacuum to separate the liquid extract from the solid residue. The solvent was then evaporated in a rotary vacuum evaporator until a half-solid residue was obtained, which was then dried at $60{ }^{\circ} \mathrm{C}$ to constant weight. The masse extracted from dry plant material defines the yield of total extractive substances known as resinoid $(y)$ in \%. Each experiment was performed in triplicate.

\subsection{Optimization of the extraction procedure using RSM model}

The optimization of extraction parameters of resinoid from $G$. verum in order to obtain the maximum yield was carried out by RSM. The independent process variables were extraction temperature $(T)$ and solvent-to-solid ratio $(S)$. RSM models were developed in the form of a second-order polynomial equation:

$$
y=b_{0}+b_{1} \times T+b_{2} \times S+b_{12} \times T \times S+b_{11} \times T^{2}+b_{22} \times S^{2}
$$

where $y$ is the resinoid yield, $T$ is extraction temperature, $S$ solvent-to-solid ratio, $b_{i}$ and $b_{i j}(i=0,1,2$ and $j=1,2)$ are the parameters of equation (1) obtained by the multiple nonlinear regression method.

The performance of developed models was assessed with various statistical criteria such as: the coefficient of determination $\left(R^{2}\right)$, the coefficient of variation $(C V)$, the adequate precision (Adec. Prec.) and the mean relative percentage deviation (MRPD) [26]. Adequate precision is a signal to noise ratio. It compares the range of the predicted values at the design points to the average prediction error. Ratios greater than 4 indicate adequate model discrimination. The mean relative percentage deviation (MRPD), calculated according to the following equation:

$$
M R P D=\frac{100}{n} \times \sum_{1}^{n}\left|\frac{y_{p, i}-y_{a, i}}{y_{a, i}}\right|
$$

where $y_{p, i}$ and $y_{a, i}$ are the predicted and actual values and $n$ is the number of experimental runs. Another way to evaluate model suitability is the lack-of-fit test. The statistical significance of the models as well as independent variables and their interactions was estimated by the ANOVA. Using developed models, the maximum predicted resinoid yields and the optimal extraction conditions were determined through the optimization with the target goal "maximum" using the Design-Expert 7.0.0 Trial software (Stat-Ease Inc., Minneapolis, MN).

\section{Results and discussion \\ 3.1 Influence of extraction parameters on the extraction yield}

As can be seen from Fig. 1, the extraction yield from $G$. verum obtained by US-AE depends on the extraction conditions. The results indicate that the extraction yield increased with the increase of $T$ and the highest resinoid yield was obtained at $40{ }^{\circ} \mathrm{C}$ at different $S$ (Fig. 1). The highest extraction yield obtained at $40{ }^{\circ} \mathrm{C}$ under the US power is in accordance with earlier reports which confirmed the positive effects of $T$ on extraction efficiency of G. mollugo [13-16]. Now, it is confirmed that extraction temperature also has significant impact on extraction yield from $G$. verum obtained using US-AE. Generally, temperature increase can accelerate the softening of the raw materials and improve the solubility of extracted compounds [27].

In this work, second variable influencing the resinoid yield from $G$. verum was $S$. Results indicate that the resinoid yield increased with the increase of $S$ at different $T$. This result is in accordance with earlier report which confirmed the positive effects of $S$ on extraction efficiency of bioactive components from grape seeds at different $T$ [28]. In our case, increasing the solvent proportion in the system improved the extraction yields and thus led to a more efficient extraction (Fig. 1), which is in agreement with the previous studies [23, 28, 29]. Fig. 1 shows that the extraction yield of $G$. verum was mainly achieved over $S$ of $20 \mathrm{~kg} \mathrm{~kg}^{-1}$. However, there was no significant difference $(P<0.05)$ of resinoid yield obtained at $S$ of 30 and $40 \mathrm{~kg} \mathrm{~kg}^{-1}$. Actually, the increase of $S$ over $30 \mathrm{~kg} \mathrm{~kg}^{-1}$ did not show significant influence on resinoid yield from Galium species.

With increased $T$ and $S$ the extraction yields varied from 6.4 to $18.1 \%$. Different levels of resinoid yield of $G$. verum reported in this and other studies $[6,30,31]$ could be ascribed to several factors, including environmental factors, cultivars, harvest time, as well as the solvent type used, extraction method, temperature and time [25].

\subsection{Response surface methodology - RSM model}

The RSM model based on second-order polynomial equation was applied to correlate changes in the resinoid yield with $T$ and $S$. The changes in the resinoid yield $(y)$ along with two operating variables ( $T$ and $S$ ) were analyzed using multiple nonlinear regression models. The second-order polynomial equation 
(Eq. (1)) was used to fit experimental data. The obtained result presents the resinoid yield $(y)$ as a function of values of extraction temperature $(T)$, and solvent-to-solid ratio $(S)$ as follows:

$$
\begin{aligned}
y= & 1.85+6.68 \times 10^{-1} \times T+1.08 \times 10^{-2} \times S \\
& +4.04 \times 10^{-3} \times T \times S+8.55 \times 10^{-3} \times T^{2}+5.61 \times 10^{-3} \times S^{2}
\end{aligned}
$$

The statistical significance of the equation model, the operating variables, their interactions and the validity of the fitting, all analyzed using ANOVA, are shown in Table 1 . The $p<0.05$ values indicate that model terms are significant. Two operating variables ( $T$ and $S$ ), their interaction and two square values $\left(T^{2}\right.$ and $S^{2}$ ) had significant impact on $y$.

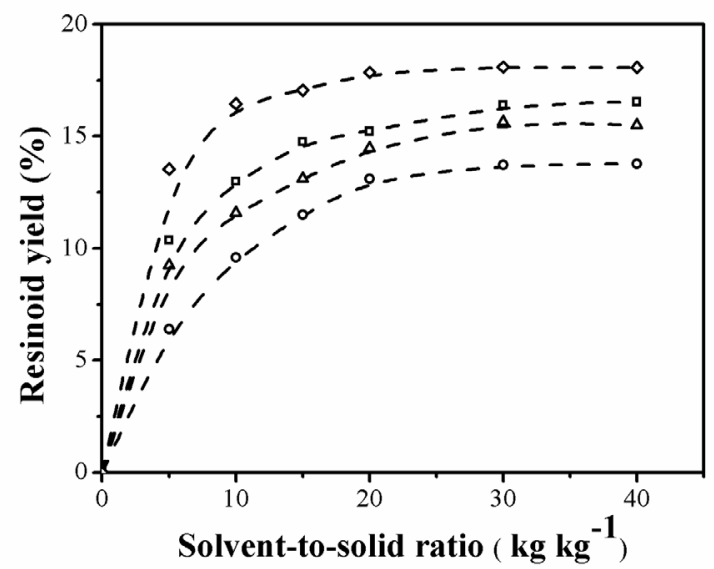

Fig. 1 The extraction yield $(y)$ from aerial part of $G$. verum as function of solvent-to-solid ratio $(S)$ at different temperatures $(T)$ : $20(\diamond), 28(\square), 34(\Delta)$ and $40(\circ){ }^{\circ} \mathrm{C}$.

\begin{tabular}{|c|c|c|c|c|c|}
\hline $\begin{array}{l}\text { Source of } \\
\text { variance }\end{array}$ & $\begin{array}{l}\text { Sum of } \\
\text { squares }\end{array}$ & $\begin{array}{l}\text { Degrees of } \\
\text { freedom }\end{array}$ & $\begin{array}{l}\text { Mean } \\
\text { square }\end{array}$ & $F$-value & $p$-Value \\
\hline Model & 447.05 & 5 & 89.41 & 140.35 & $<0.0001$ \\
\hline$T$ & 212.40 & 1 & 212.40 & 333.41 & $<0.0001$ \\
\hline$S$ & 172.12 & 1 & 172.12 & 270.18 & $<0.0001$ \\
\hline$T S$ & 6.79 & 1 & 6.79 & 10.66 & 0.0022 \\
\hline$T^{2}$ & 37.90 & 1 & 37.90 & 59.49 & $<0.0001$ \\
\hline$S^{2}$ & 7.06 & 1 & 7.06 & 11.09 & 0.0018 \\
\hline Residual & 26.75 & 42 & 0.63 & & \\
\hline Lack of Fit & 14.77 & 18 & 0.82 & 1.65 & $0.1267^{*}$ \\
\hline Pure Error & 11.98 & 24 & 0.49 & & \\
\hline The total correc. & 473.80 & 47 & & & \\
\hline$R^{2}$ & 0.979 & & & & \\
\hline$C V$ & 3.33 & & & & \\
\hline Adeq Precision & 71.09 & & & & \\
\hline$M R P D$ & $\pm 2.8 \%$ & & & & \\
\hline
\end{tabular}

Table 1 Analysis of variance for the second-order polynomial model.

$T$ - temperature; $S$ - solvent-to-solid ratio; $R^{2}$ - coefficient of determination; $C V$ - coefficient of variation; $M R P D$ - mean relative percentage deviation. *Statistically not significant at the confidence level of $95 \%$.
Work was focused our attention onto statistical criteria indicating the adequacy, reliability and precision of the developed RSM model (Table 1 and Fig. 2). The statistical significance of the RSM model was estimated based on difference between calculated and tabulated $F$ value $\left(F_{\text {tab }}=2.63\right)$, along with the $p$-value less than 0.05 . RSM model was statistically significant at the confidence level of $95 \%$. Another way to evaluate model suitability is the lack-of-fit test. The $R^{2}$ values (Table 1) approximately equal to one proved a good fit by the second-order polynomial equation. Relatively low values of the $C V$ (Table 1) indicated the remarkable precision and reliability of the model. The values of Adeq. Precision which measures the signal to noise ratio, are much greater than 4 , so the model can be used to navigate the design space. The low values $( \pm 2.8 \%)$, also implied the reliability and accuracy of the developed model. There was no significance in the lack of fit $(p>0.05)$ which indicated that the model could be used to predict the responses.

Diagnostic plots are shown in Fig. 2. The residuals were close to the straight line and evenly distributed around it, confirming the normal distribution of residuals and validating the ANOVA results (Fig. 2A). The values of Cook's distance, shown in Fig. $2 \mathrm{~B}$, were far below the limit of 0.8 , indicating that there were no outliers in the experimental data sets. Random scattering of dots around diagonal could be observed by comparing the predicted and actual values of $y$ (Fig. 2C).

RSM was used to explain the effect of $T$ and $S$ on resinoid yield extracted from the G. verum (Table 1). The resinoid yield as a function of $T$ and $S$ is shown in the form of Eq. (3). The resinoid yield increased with $T$ and $S$ increasing which promoted the solubility and mass transfer rate of resinoid (Fig. 1). Also, viscosity and surface tension of the extracting solvent were reduced at higher $T$, which facilitated the penetration of the solvent into the plant particles, improving the extraction yield [26]. While, on the other hand, increasing the amount of solvent favorably modifies the final equilibrium state and increases the driving force for the mass transfer, i.e. the concentration difference between the solid and the liquid phase [32, 33].

The RSM model proved the impact of extraction techniques, time and temperature on extraction yield of Galium species [15]. In this work, we used RSM model to examine the effect of $S$ on the yield of Galium species. The solvent-to-solid ratio was also a vital factor for increasing the yield of bioactive components, since increased solvent-to-solid ratio could facilitate the access of the solute to the solvent [18]. In addition, cavitation is known to produce a series of mechanical effects, such as particle collisions and cell wall disruption [34], which promote penetration of the solvent into the sample matrix and increase rates of mass transfer for bioactive components [35].

In fact, an RSM study is a very important tool for delineation of the process, which provides the knowledge about effects of process variables such as solvent-to-solid ratio and temperature on the extraction yield. These parameters are then used 
to predict extraction process and, in this way, to estimate the viability of the process on an industrial scale.

A

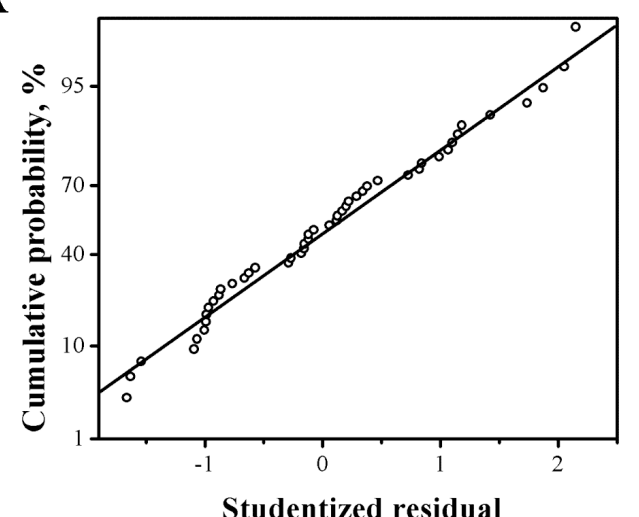

B

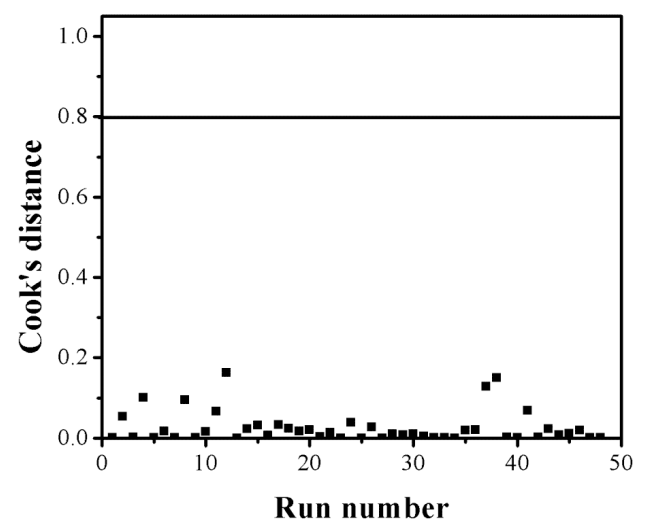

$\mathcal{C}$

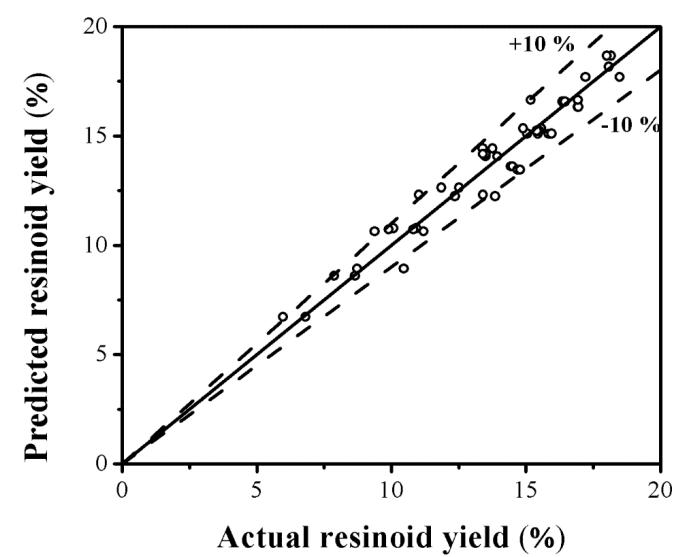

Fig. 2 Diagnostic plots: normal probability plot of residuals (A), Cook's distance (B) and predicted and actual values of retinoid yield (C).

\subsection{Optimization the ultrasound assistant extraction (US-AE) by RSM model}

The maximum predicted value of the resinoid yield was found through the optimization by the RSM model. The maximum predicted $y$, corresponding to $T$ of $40{ }^{\circ} \mathrm{C}$ and $S$ of $30 \mathrm{~kg} \mathrm{~kg}^{-1}$, was $18.7 \%$. This value was in accordance with the resinoid yield (18.1\%) obtained at $40{ }^{\circ} \mathrm{C}$ and $30 \mathrm{~kg} \mathrm{~kg}^{-1}$ thus verifying the developed model. The relative deviation between predicted and experimentally obtained values of resinoid yield at the optimal model conditions is $\pm 3.3 \%$. The confirmed validity of the RSM under optimal conditions is in agreement with the previous studies $[15,25,36]$.

In this work, for the first time, the resinoid extraction from $G$. verum was studied using a statistical method based on the RSM model in order to identify and quantify the variables able to maximize the relative US extraction efficiency. Hence, US-AE is being widely used in the extraction of bioactive compounds from natural sources for use in food industry [37]. Furthermore, use of ultrasound reduces the use of toxic solvents, which is desirable for extracting bioactive compounds for human consumption [18]. Milić and coworkers [15] reached better extraction yield from Galium species with RSM model using the ethanol aqueous solution for US-AE. However, a better extraction yield does not necessarily mean a higher content of desired components, since ballast substances present in higher percentage reduce the portion of bioactive components [38]. Importance of this study, as well, is the fact that we use effective solvent, such as ethanol, for solid-liquid US extraction, in order to minimize impact on human health. The current food industry adopts US technique and focuses on extracting and recovering valuable active compounds from different plant materials [18, 21, 33, 39]. Therefore, our research suggests combined use of numerical modeling and ultrasound in extraction of active components from $G$. verum for traditionally food manufacturing in order to improve productivity and reduce operational cost.

\section{Conclusion}

The response surface methodology (RSM) optimization methods employed in the present work have not been earlier used for optimizing the extraction of total extractive substances from G. verum by ultrasound-assisted extraction (US-AE). In this work, RSM has been employed for the first time for evaluating the effects of the extraction process variables such as temperature $(T)$ and solvent-to-solid ratio $(S)$ on total extractive substances from $G$. verum in the presence of ultrasound; as well as to optimize operational parameters of US-AE in order to obtain a maximal possible extraction yield from $G$. verum. The obtained experimental data was adequately fitted into second-order polynomial models with coefficient of determination $\left(R^{2}\right)$ of 0.979 . The RSM model pointed out the impact of $S$ and $T$ on extraction yield of $G$. verum. Also, RSM was successfully applied to obtain set of optimal parameters for increasing the US-AE efficiency from G. verum. RSM showed that the optimal extraction parameters, which gave a maximum extraction yield of $18.7 \%$, were obtained for $40{ }^{\circ} \mathrm{C}(T)$ and $30 \mathrm{~kg} \mathrm{~kg}^{-1}$ $(S)$. Using the modeled optimized conditions, the detected relative difference between predicted and experimental yield was $\pm 3.3 \%$. Results of this work showed that RSM proved as useful and new tool for optimizing the extraction of total extractive substances from $G$. verum. 
The RSM as numerical modeling offers an affordable, fast and efficient means to characterize and optimize US processes $[15,22]$. A numerical modeling must be a mathematical tool that reflects the physical behavior of the actual structure and experimental observations [40]. Methodologies that are not standardized and control parameters are the main reasons why in food industry numerical modeling cannot be widely applied in research yet. The RSM model was proved as easy, acceptable, accurate and useful tool for the standardization of extraction conditions for bioactive component from important food industry plants. Numerical modeling can for instance be utilized to simplify explanation of phenomena, optimize extraction processes, reduce operational cost and improve productivity $[15,21]$.

\section{Acknowledgement}

The project presented in this article is supported by the Ministry of Education, Science and Technological Development of the Republic of Serbia, Projects OI175034 and OI173048.

\section{References}

[1] Jarić, S., Popović, Z., Macukanović-Jocić, M., Djurdjević, L., Mijatović, M., Karadzić, B., Mitrović, M., Pavlović, P. "An ethnobotanical study on the usage of wild medicinal herbs from Kopaonik Mountain (Central Serbia)." Journal of Ethnopharmacology. 111(1), pp. 160-75. 2007. https://doi.org/10.1016/j.jep.2006.11.007

[2] Nikolić, V., Sigunov, A., Diklić, N. "Appendix of the Flora of Serbia by new data for distribution plant species." Serbian Academy of Sciences and Arts, Belgrade. 1986.

[3] Calvo, M. I., Cavero, R. Y. "Medicinal plants used for neurological and mental disorders in navarra and their alidation from official sources." Journal of Ethnopharmacology. 169, pp. 263-268. 2015. https://doi.org/10.1016/j.jep.2015.04.035

[4] Bisset, N. G., Wichtl, M. "Herbal Drugs and Phytopharmaceuticals." DC: CRC Press, Boca Raton, London, New York, Washington. 2001. URL: http://www.abebooks.com/book-search/title/herbal-drugs-andphytopharmaceuticals/

[5] Ilina, T. V., Kovaleva, A. M., Goryachaya, O. V. "Essential oil from Galium verum flowers." Chemistry of Natural Compounds. 45, pp. 587-588. 2009. https://doi.org/10.1007/c10600-009-9375-1

[6] Lakić, N.S., Mimica-Dukić, N. M., Isak, J. M., Božin, B.N. "Antioxidant properties of Galium verum L. (Rubiaceae) extracts." Central European Journal of Biology. 5, pp. 331-337. 2010.

https://doi.org/10.2478/s11535-010-0022-4

[7] Corrigan, D., Timoney, F. R., Donnelly, M. X. D. "Iridioids and Alkanes in Twelve Species of Galium and Asperula." Phytochemrstry. 17, pp. 1311-1313. 1978. https://doi.org/10.1016/S0031-9422(00)94304-8

[8] Bokhari, J., Khan, R. M, Shabbir, M., Rashid, U., Jan, S., Zai, A. J. "Evaluation of diverse antioxidant activities of Galium aparine." Spectrochim Acta A. 102, pp. 24-29. 2013. https://doi.org/10.1016/j.saa.2012.09.056

[9] Yigit, D., Yigit, N., Ozgen, U. "An investigation on the anticandidal activity of some traditional medicinal plants in Turkey." Mycoses. 52, pp. 135-140. 2008. https://doi.org/10.1111/j.1439-0507.2008.01552.x

[10] Zhao, C. C., Shao, J. H., Li. X., Xu, J., Wang, J. H. "A new anthraquinone from Galium verum L." Natural Product Research. 20(11), pp. 981-984. 2006. https://doi.org/10.1080/14786410600921532
[11] Zhao, C. C., Shao J. H., Li, X., Kang, X. D., Zhang, Y. W., Meng, D. L., Li, N. "Flavonoids from Galium verum L." Journal of Asian Natural Products Research. 10(7-8), pp. 613-7. 2008.

https://doi.org/10.1080/10286020802133217

[12] Zhao, C. C., Shao, J. H., Zhao, C. J., Li, X. "A new flavonoid glycoside from Galium verum." Chemistry of Natural Compounds. 47(4), pp. 545546. 2011. https://doi.org/10.1007/s10600-011-9992-3

[13] Milić, P. S., Bekrić, D. M., Milić, S. M., Rajković, K. M. "A study of the extraction kinetics of the minerals from the white lady's bedstraw (Galium mollugo L.) by using an artificial neural network." Hemijska Industrija. 65, pp. 313-321. 2011. https://doi.org/10.2298/HEMIND110125013M

[14] Milić, P. S., Stanojević, Lj., Rajković, K. M., Milić, S. M., Nikolić, V. V., Nikolić, Lj., Veljković, B. V. "Antioxidant activity of Galium mollugo L. extracts obtained by different recovery techniques." Hemijska Industrija. 67, pp. 89-94. 2013. https://doi.org/10.2298/HEMIND120314042M

[15] Milić, P. S., Rajković, K. M., Stamenković S. O., Veljković, B. V. "Kinetic modeling and optimization of maceration and ultrasound-extraction of resinoid from the aerial parts of white lady's bedstraw (Galium mollugo L.)." Ultrasonics Sonochemistry. 20, pp. 525-534. 2013.

https://doi.org/10.1016/j.ultsonch.2012.07.017

[16] Milić, P. S., Rajković, K. M., Milićević, P. M., Milić, S. M., Brdarić, T. P., Pavelkić, V. M. "Comparison, artificial neural network modeling and genetic algorithm optimization of the resinoid and potassium yields from white lady's bedstraw (Galium mollugo L.) by conventional, reflux and ultrasound-assisted aqueous-ethanolic extraction." Chemical Industry and Chemical Engineering Quarterly. 19, pp. 141-152. 2013.

https://doi.org/10.2298/CICEQ120316049M

[17] Chan, C. H., Yusoff, R., Ngoh G. C. "Modeling and kinetics study of conventional and assisted batch solvent extraction." Chemical Engineering Research and Design. 92, pp. 1169-1186. 2014.

https://doi.org/10.1016/j.cherd.2013.10.001

[18] He, B., Zhang, L. L., Yue, X. Y., Liang, J., Jiang, J., Gao, X. L., Yue, P. X. "Optimization of ultrasound-assisted extraction of phenolic compounds and anthocyanins from blueberry (Vaccinium ashei) wine pomace." Food Chemistry. 204, pp. 70-76. 2016. https://doi.org/10.1016/j.foodchem.2016.02.094

[19] Tao, Y., Zhang, Z., Sun, D. W. "Kinetic modeling of ultrasound-assisted extraction of phenolic compounds from grape marc: Influence of acoustic energy density and temperature." Ultrasonics Sonochemistry. 21, pp. 1461-1469. 2014. https://doi.org/10.1016/j.ultsonch.2014.01.029

[20] Toma, M., Vinatoru, M., Paniwnyk, L., Mason, T. J. "Investigation of the effects of ultrasound on vegetal tissues during solvent extraction." Ultrasonics Sonochemistry. 8, pp. 137-142. 2001. https://doi.org/10.1016/S1350-4177(00)00033-X

[21] Pingret, D., Fabiano-Tixier, A. S., Le Bourvellec, C., Renard, C. M. G. C., Chemat, F. "Lab and pilot-scale ultrasound-assisted water extraction of polyphenols from apple pomace." Journal of Food Engineering. 111, pp. 73-81. 2012. https://doi.org/10.1016/j.jfoodeng.2012.01.026

[22] Rosello-Soto, E., Galanakis, C. M., Brncic, M., Orlien, V., Trujillo F. J., Mawson, R., Knoerzer, K., Tiwari, B. K., Barba, F. J. "Clean recovery of antioxidant compounds from plant foods, byproducts and algae assisted by ultrasounds processing. Modeling approaches to optimize processing conditions." Trends in Food Science \& Technology. 42, pp. 134-149. 2015. https://doi.org/10.1016/j.tifs.2015.01.002

[23] Cheok, C. Y., Chin, N. L., Yusof, Y. A., Talib, R. A., Law, C. L. "Optimization of total phenolic content extracted from Garcinia mangostana Linn. hull using response surface methodology versus artificial neural network." Industrial Crops and Products. 40, pp. 247-253. 2012. https://doi.org/10.1016/j.indcrop.2012.03.019 
[24] Medouni-Adrar, S., Boulekbache-Makhlouf, L., Cadot, Y., MedouniHaroune, L., Dahmoune, F., Makhoukhe, A., Madani, K. "Optimization of the recovery of phenolic compounds from Algerian grape by-products." Industrial Crops and Products. 77, pp. 123-132. 2015. https://doi.org/10.1016/j.indcrop.2015.08.039

[25] Simić, M. V., Rajković, M. K., Stojičević, S. S., Veličković, T. D., Nikolić, Č. N, Lazić, L. M., Karabegović, T. I. "Optimization of microwave-assisted extraction of total polyphenolic compounds from chokeberries by response surface methodology and artificial neural network." Separation and Purification Technology. 160, pp. 89-97. 2016. https://doi.org/10.1016/j.seppur.2016.01.019

[26] Kostić, M. D., Joković, N. M., Stamenković, O. .S, Rajković, K. M., Milić, P. S, Veljković V. B. "Optimization of hempseed oil extraction by n-hexane." Industrial Crops and Products. 48, pp. 133-143. 2013. https://doi.org/10.1016/j.indcrop.2013.04.028

[27] Tao, Y., Sun, D. W. "Enhancement of food processes by ultrasound: a review." Critical Reviews in Food Science and Nutrition. 55, pp. 570-594. 2015. https://doi.org/10.1080/10408398.2012.667849

[28] Bucić-Kojić, A., Planinić, M., Tomas, S., Bilić, M., Velić, D. "Study of solid-liquid extraction kinetics of total polyphenols from grape seeds." Journal of Food Engineering. 81, pp. 236-242. 2007. https://doi.org/10.1016/j.jfoodeng.2006.10.027

[29] Said, K. A. M., Yakub, I., Alipah, N. A. M. "Effects of Solvent/Solid Ratio and Temperature on the Kinetics of Vitamin C Extraction from Musa Acuminata." Journal of Applied Science \& Process Engineering. 2(2), pp. 107-115. 2015.

https://doi.org/10.4028/www.scientific.net/AMM.833.78

[30] Demirezer, L. O., Gurbuz, F., Guvenalp, Z., Stroch, K., Zeeck, A. "Iridoids, flavonoids and monoterpene glycosides from Galium verum subsp. verum." Turkish Journal of Chemistry. 30, pp. 525-534. 2006. URL: http://journals.tubitak.gov.tr/chem/issues/kim-06-30-4/kim-30-413-0504-17.pdf

[31] Shafaghat, A., Salimi, F., Aslaniyan, N., Shoaei, Z. "Flavonoids and an ester derivative isolated from Galium verum." World Appled Sciences Journal. 11, pp. 473-477. 2010. URL: http://www.idosi.org/wasj/ wasj11(4)/16.pdf

[32] Cacace, J. E., Mazza, G. "Mass transfer process during extraction of phenolic compounds from milled berries." Journal of Food Engineering. 59, pp. 379-389. 2003. https://doi.org/10.1016/S0260-8774(02)00497-1
[33] Cisse, M., Bohuon, P., Sambe, F., Kane, C., Sakho, M., Dornier, M. "Aqueous extraction of anthocyanins from Hibiscus sabdariffa: Experimental kinetics and modeling." Journal of Food Engineering. 109, pp. 16-21. 2012. https://doi.org/10.1016/j.jfoodeng.2011.10.012

[34] Chemat, F., Huma, Z., Khan, M. K. "Applications of ultrasound in food technology: processing, preservation and extraction." Ultrasonics Sonochemistry. 18(4), pp. 813-835. 2011. https://doi.org/10.1016/j.ultsonch.2010.11.023

[35] Avhad, D. N., Rathod, V. K. "Ultrasound assisted production of a fibrinolytic enzyme in a bioreactor." Ultrasonics Sonochemistry. 22, pp. 257264. 2015. https://doi.org/10.1016/j.ultsonch.2014.04.020

[36] Rajković, K., Pekmezović, M., Barac, A., Nikodinović- Runić, J., ArsićArsenijevic, V. "Ihibitory effect of thyme and cinnamon essential oils on Aspergillus flavus: Optimization and activity prediction model development." Industrial Crops and Products. 65, pp. 7-13. 2015. https://doi.org/10.1016/j.indcrop.2014.11.039

[37] Corbin, C., Fidel, T., Leclerc, E. A., Barakzoy, E., Sagot, N., Falguieres, A. "Development and validation of an efficient ultrasound assisted extraction of phenolic compounds from flax (Linum usitatissimum L.) seeds." Ultrasonics Sonochemistry. 26, pp. 176-185. 2015. https://doi.org/10.1016/j.ultsonch.2015.02.008

[38] Ranić, M., Nikolić, M., Pavlović, M., Buntić, A., Siler-Marinković, S., Dimitrijević-Branković, S. "Optimization of microwave-assisted extraction of natural antioxidants from spent espresso coffee grounds by response surface methodology." Journal of Cleaner Production. 80, pp. 69-79. 2014. https://doi.org/10.1016/j.jclepro.2014.05.060

[39] Casazza, A. A., Aliakbarian, B., Mantegna, S., Cravotto, G., Perego, P. "Extraction of phenolics from Vitis vinifera wastesusing non-conventional techniques." Journal of Food Engineering. 100(1), pp. 50-55. 2010. https://doi.org/10.1016/j.jfoodeng.2010.03.026

[40] Toda, A. T., Sawada, M. M., Rodrigues, C. E. C. "Kinetics of soybean oil extraction using ethanol assolvent: Experimental data and modeling." Food and Bioproducts Processing. 98, pp. 1-10. 2016. https://doi.org/10.1016/j.fbp.2015.12.003 